\title{
Benign recurrent intrahepatic cholestasis
}

INSERM

\section{Source}

INSERM. (1999). Orphanet: an online rare disease and orphan drug data base. Benign recurrent intrahepatic cholestasis. ORPHA:65682

Benign recurrent intrahepatic cholestasis (BRIC) is a hereditary liver disorder characterized by intermittent episodes of intrahepatic cholestasis, generally without progression to chronic liver damage. BRIC is now believed to belong to a clinical spectrum of intrahepatic cholestatic disorders that ranges from the mild intermittent attacks in BRIC to the severe, chronic and progressive cholestasis seen in progressive familial intrahepatic cholestasis (PFIC; see this term). 